\title{
Marriage and parenthood preferences among college students in China
}

\author{
Sampson Lee Blair ${ }^{{ }^{*}}$ (D) and Timothy J. Madigan ${ }^{2}$
}

\author{
* Correspondence: \\ slblair@buffalo.edu \\ 'Department of Sociology, The \\ State University of New York, \\ Buffalo, NY 14260, USA \\ Full list of author information is \\ available at the end of the article
}

\begin{abstract}
Using data from a recent survey of Chinese college students, this study examines the contextual factors associated with young adults' preferences for marriage and parenthood. The analyses demonstrate that females and males prefer a later age at marriage, less than two children, and a relatively short timing between marriage and first birth. Pro-natalist attitudes and religiosity are shown to significantly influence childbearing preferences, while parental characteristics have a strong association with males' preferences, but comparatively less with females'. The analyses suggest that young Chinese adults are still influenced by traditional cultural expectations, but that individual traits are also important. The potential influence of cultural globalization and changing Chinese gender roles are discussed.
\end{abstract}

Keywords: Marriage, Parenthood, China, Childbearing, Gender

Within China, tremendous social change, particularly in terms of economic growth, has created a variety of effects upon individuals making the transition into early adulthood. Over recent decades, educational attainment has increased for both females and males (Li 1994; Wu and Zhang 2010), leading to increased occupational opportunities for young adults. Traditional cultural standards concerning intimate relationships have similarly changed, with sexual activity among young, unmarried, adults increasing (Chi et al. 2015; Feng and Quanhe 1996). In matters of mate selection, the traditional role of parents has lessened considerably, and young adults now exercise considerable individual choice (Xu 1994). In the face of social change, however, becoming married is still recognized as a primary goal for young adults in China (Evans 1997; To 2015) and bearing children is, understandably, strongly encouraged (Wu et al. 2014). Despite the seemingly universal acceptance that marriage and parenthood are expected outcomes for young Chinese adults, females and males often face different challenges and bring different perspectives in the pursuit of these goals.

Traditional stereotypes of young women and men seemingly persist within Chinese culture (Jankowiak and Li 2014), wherein males are viewed as serious, ambitious, stubborn, independent, and powerful, while females are regarded as quiet, gentle, shy, and jealous. In the pursuit of a partner, a strong double standard still exists, with females and males having decidedly different objectives and preferences (Piotrowski et al. 2016). Women are cast as seeking a male partner who is intelligent and wealthy (Wang and Abbott 2013), while men are viewed as seeking a female partner whose primary attribute is her physical beauty (Xia and Zhou 2003). Even after finding a potential partner, females and males are

(c) The Author(s). 2018 Open Access This article is distributed under the terms of the Creative Commons Attribution 4.0 International License (http://creativecommons.org/licenses/by/4.0/), which permits unrestricted use, distribution, and reproduction in any medium, provided you give appropriate credit to the original author(s) and the source, provide a link to the Creative Commons license, and indicate if changes were made. 
expected to take different paths, with Chinese women being expected to marry at an earlier age, while they still have a youthful appearance and can bear children, and Chinese men being expected to marry later, after they have achieved financial success and stability (Piotrowski et al. 2016).

In regards to expectations concerning intimate relationships, contemporary young adults in China tend to be more progressive, as compared to their parents, yet mothers and fathers continue to exert a significant amount of influence over their children, and particularly in terms of their dating behaviors (Chen 2009; Wu 1996). Among young adults, the desire to obtain higher educational attainment typically places them within a college or university environment, where dating and even the open display of affection (e.g., holding hands, kissing in public) have become an increasingly commonplace (Xia and Zhou 2003; Yang 2011). Recent studies have suggested that sexual activity among Chinese college students is increasing (Lei 2005), suggesting that dating, itself, may be regarded as a purely pleasurable relationship, as opposed to being a direct pathway to marriage and parenthood. As educational attainment has increased, and particularly with women's enrollment rates exceeding those of men (Wu and Zhang 2010), researchers have noted that higher educational attainment tends to decrease Chinese women's likelihood of marriage, yet it significantly increases that of men (Tian 2013).

Patterns of marriage and childbearing have been examined across multiple societies, and consideration has been given to a multitude of related factors. In the case of contemporary China, becoming married and having children continues to be a central goal for young adults, and most tend to achieve these goals (Santos and Harrell 2017). Overlooked within these patterns, however, is a broader understanding of the specific preferences for marriage and parenthood among young adults. The need for greater understanding of how contemporary Chinese young adults find a partner has been noted by researchers (Xu et al. 2000), as well as the need to more precisely examine the preferential dimensions of relationship formation (Hu and Scott 2016) and how these might vary among women and men (Shek 2006). Using a sample of Chinese college students, this study will examine the preferences for marriage and childbearing among young adults in contemporary China. Specifically, this study will attempt to more accurately assess the nature of such preferences, and how they may be influenced by individual and familial traits.

\section{Marriage and parenthood within the Chinese context}

In traditional Chinese culture, marriage is regarded as a universal goal for all individuals (Evans 1997), as being married, in conjunction with having children, brings about an elevation of social status, inclusion, and acceptance within the community, and also provides for the unbroken continuation of family lineage (Hesketh 2009; To 2015). According to the 2000 census, better than $95 \%$ of females and males had married at least once, before reaching 40 years of age (Davin 2007). Understandably, cultural tradition also strongly links marriage with parenthood, thus making having children an expected and socially necessary addition to marriage, itself. Although fertility rates have been quite low for several decades in China, the cultural expectation for having children remains quite strong (Basten and Jiang 2015). During the 1980s, the number of children considered ideal by Chinese women was approximately 2.1, yet this number dropped during the 1990s, and in the period between 2000 and 2011, the desired 
number of children dropped to 1.69 (Jiawei 2015). This decline in the number of desired children is partially a function of the government's One-Child Policy, although parents' concerns about the costs of children's educational attainment may be partially responsible (Liu 2012). Educational attainment may affect fertility preferences in other manners, as fertility rates may be inversely related to women's educational and occupational attainment (Wu et al. 2014), and educational attainment may infuse more egalitarian ideologies concerning marriage and fertility (Mason 1987).

During the twentieth century, China experienced a wide variety of social, political, economic, and cultural change. In conjunction with the New Marriage Law, which discouraged arranged marriages and strongly supported individual choice (Parrish and Farrer 2000), the Chinese government also instituted new policies concerning childbearing, effectively lessening the importance of family characteristics (Xu and Whyte 1990). Specifically, the theme of these policies became known as "later, longer, and fewer," which promoted the notions that young adults should wait until "later" to marry, allow for a "longer" before having their first child, and subsequently have "fewer" children. As a result of these policies, the average age at marriage began to increase (Feeney and Wang 1993), resulting in later marriage for young adults. This pattern of later age at first marriage has been shown to have continued through the remainder of the twentieth century and has established a pattern which still exists, currently (Cai and Wang 2014).

During the 1980s, the average age at first marriage began to decrease, suggesting that cultural traditions concerning marriage were beginning to reappear (Davis and Harrell 1993). This trend was relatively short lived, as the average age at first marriage began to climb during the 1990s, largely as a result from the higher educational attainment by both females and males, but also due to a growing desire among young adults to attain financial stability and independence (Parrish and Farrer 2000). At the same time, the population of unmarried males began to increase during the 1990s, and particularly those with less education (Lee and Wang 1999). As of 2005, approximately $2 \%$ of women and 10\% of men between the ages of 30 and 34 remained unmarried (Jones and Gubhaju 2009), suggesting that marriage is both highly desired and highly achieved within the population and that males are facing a considerable challenge. As of December of 2015, the government declared that the One-Child policy would be amended, so as to allow couples to have two or more children (see Attane 2016). While the structures and norms concerning Chinese marriage and fertility have a long and complex history, being subjected to a variety of social forces, the contemporary mode appears to be one in which individuals begin their relationships with considerable choice, and qualities of attraction, both physical and emotional, as well as the open display of affection and attachment, have rapidly become the cultural norm (Gaetano 2008).

Prior to the application of the One-Child Policy, married Chinese couples did not rush into having children immediately after marriage. Indeed, couples waited approximately two and a half years before having their first child (the wait was slightly longer among rural couples) (Feng and Quanhe 1996). Interestingly, after the One-Child Policy began, the age at marriage began to increase, while the gap between marriage and first birth began to decrease (Feng and Quanhe 1996). While seemingly contradictory, researchers have suggested that since couples were marrying at later ages, they felt compelled to shorten the interval between marriage and first birth in order to "catch up" (Hong 2006). This shortening of the interval between marriage and first birth 
certainly reflects a strong preference to begin parenthood as quickly as possible (Qian and Knoester 2015), yet the broader cultural underpinnings of such preferences cannot be overlooked.

Tang and Zhou (2000) compared Chinese and American college students in a cross-cultural study of dating. Chinese culture, they note, emphasizes the collective rather than the individual, thus stipulating obedience of authority figures, such as parents and school personnel, along with an instrumental approach to courtship. The majority of Chinese college students in their sample had no dating experience and, among those who did, the average age at which dating began was 18 . Only one thirds of students reported that they were currently dating someone. In comparison to their American counterparts, Chinese students began dating at older ages, dated less frequently, and such relationships were less likely to develop into sexual relationships (Tang and Zhou 2000).

\section{Gender and the timing of marriage and parenthood}

Given the nature of marriage and parenthood within China's long cultural history, researchers have noted that females and males typically approach such relationships with notably distinct preferences and desired outcomes. Indeed, the strong preference for bearing sons is derived from the traditional practice of sons assuming the rights to all inheritance of their parents. Upon marriage, sons were expected to bring their wives into the home of their parents, where the new daughters-in-law would be expected to provide for the care of their husbands' parents. Daughters, on the other hand, would be married out of their respective families, quite literally, as they would no longer be considered members of their families of orientation, following their marriage. Married women would therefore have no claim to the property of their own parents, nor of the parents of their husbands (Bian et al. 1998).

Gender roles within Chinese culture have changed considerably over the past several decades. Parrish and Farrer (2000) suggest that these changes may be due to a combination of micro-level mechanisms of bargaining (e.g., within couples' relationships) and macro-level changes in existing social institutions (specifically, educational and occupational). Building upon family exchange theory, economic independence theory (Willis 1987) assumes that roles within marriage are highly specialized, on a societal scale. As such, males are attracted to marriage because of the household labor and childcare to be provided by their wives (Becker 1981), while women are attracted to marriage because of the financial and instrumental support which their husbands can provide. However, when there is an increase in women's labor force participation, thereby reducing their dependency upon a husband, women will be less attracted to marriage. An increase in earnings potential, such as achieving a higher level of educational attainment, can similarly reduce the appeal of marriage for women.

Over the past several decades, the educational and occupational attainment of Chinese women has increased significantly (Nakano 2016; Yu and Xie 2015), thus affecting their experiences in mate selection. As such, women can wield more power within the bargaining and decision-making processes that take place within personal relationships (Gittings 2006; Guthrie 2008). As mentioned, previously, the New Marriage Law of 1950 was intended to bring about equality of the sexes within marriage, though, it can be argued that the central aim was to counter the patriarchal traditions which had long existed. The Chinese government similarly advocated equal employment 
opportunities for women and men, which led to substantial increases in the female labor participation rate during the 1970s (Cooke 2001). Economic independence theory would thus posit that the higher levels of educational and occupational attainment by women will make marriage and childbearing less appealing to them (see Qian and Qian 2014), thereby bringing about higher ages at first marriage and first birth. Researchers have noted that, in societies where women have traditionally assumed the primary burden for household labor and childcare, higher educational attainment by women effectively lowers their desire to marry (e.g., Ono 2003). In addition, greater occupational opportunities for women in Asia have been shown to substantially lower their preference for childbearing (e.g., McDonald 2013).

Explanations concerning the preferences of women and men for marriage and childbearing must also recognize the structure of the mate selection pool, as the sex ratio of the marriage market in China is highly skewed. It is estimated that among individuals seeking first marriage, the sex ratio will be approximately 150 males for every 100 females by the year 2020 (Jiang et al. 2014). Such a skewed sex ratio could potentially provide women with even greater bargaining power, particularly in terms of marriage and fertility preferences. Within the parameters of economic independence theory, women, by virtue of their scarcity, would have greater value and could assume a stronger bargaining position in matters pertaining to marriage and childbearing. Sprecher (1988) argues that the relative scarcity of women improves their dyadic power within relationships (Ellingson et al. 2004), allowing women to exercise control over the preference for marriage, the timing of marriage, and childbearing decisions within marriage. Researchers have noted that Chinese women have become increasingly selective, preferring men with higher salaries, more prestigious occupations, and better living quarters (Liu 2005). Indeed, many well-educated women often find themselves at odds with cultural expectations of marriage and their pursuit of educational and occupational opportunities (Yingchun 2015). Married couples in China are increasingly equal partners, with approximately $40 \%$ of husbands and wives having the same amount of educational attainment and 20\% of wives having more than their husbands (Parrish and Farrer 2000). It is logical to assume that men, on average, will be at a disadvantage in regard to controlling their preferences for marriage and childbearing and that this disadvantage will be particularly evident among males with less social capital (Peng 2004).

Researchers have repeatedly noted that attitudes concerning intimate relationships are affected by the cultural context (Chen et al. 2009; Hynie et al. 2006; Sprecher 1988; Yan 2003). One perspective, developmental idealism (see Thornton 2005), proposes that modernization brings about a distinct set of family traits-later ages at first marriage, lower fertility rates, an emphasis upon the nuclear family, egalitarianism, and the acceptability of divorce. Shifts toward these family traits have been noted (see Pimentel 2000) in China and may suggest that the influence of "Western" ideologies concerning marriage and childbearing preferences are quite salient (Hatfield and Rapson 2005). However, patriarchal ideologies have grown in recent years, suggesting a return to more Confucian-based expectations (Fincher 2014). If so, Chinese men who espouse more traditional ideologies concerning marriage may find their search for a partner to be difficult, given that Chinese women, on average, may prefer partners whose ideologies are more consistent with women's equal status within relationships, and particularly in regards to marriage (see Parrish and Farrer 2000). The potential return to more 
traditional preferences has also been noted among females, who still seek men with higher educational attainment, income, and home ownership (Li and Xu 2004).

Hence, the premise of economic independence theory is that increased social status of women may affect preferences for marriage and childbearing, yet it is also necessary to recognize that these preferences develop within a given cultural context. Younger cohorts of females and males, due to their greater exposure to Western culture and individualism, may develop preferences for marriage and childbearing in a different manner from the previous generation. However, long-standing norms, such as filial obligation, are still a salient element of Chinese culture (Chui and Hong 2006; Chu and Yu 2010) and may also influence preferences for marriage and childbearing. In order to better understand the nature of such preferences, and how they may differ between females and males, an analysis of college students, who are transitioning into adulthood, is warranted.

\section{Data and methods}

Data for this study were collected during 2015 and 2016 at public universities in the cities of Nanjing, Shanghai, and Wuhan. Students were randomly approached and asked to participate in a survey concerning dating and romantic relationships. Of those approached, $85 \%$ agreed to participate, and completed the survey. Following the tabulation of responses, 35 cases were eliminated due to incomplete responses, resulting in a sample of 648 students (378 females and 270 males). The sample of students ranged in ages from 18 to 22, who were all currently enrolled at their respective universities. In regard to relationship status, all of the students in the sample were single and never married. Among females, $47.1 \%$ described themselves as "currently dating someone," while $49.3 \%$ of males described themselves as likewise. The sample thus draws from a population of young adults who are attending urban Chinese universities. Any generalizations drawn from the analyses should be limited to that population. The data are available, upon request, from the authors.

A variety of questions were used to assess respondents' preferences and aspirations concerning future marriage and parenthood. In regard to marriage, participants were asked how much they agreed with the following statement: "I would like to get married someday." Responses to this item ranged from "strongly disagree" (1) to "strongly agree" (5). In addition, respondents were asked at what age, ideally, they would like to get married. In terms of parenthood, respondents were asked: "Ideally, how many children would you like to eventually have?" In conjunction with this query, respondents were also asked at what age, ideally, they would like to start having children. Together, these items provide a broad range of assessment concerning marriage and parenthood preferences, as these items directly tap into the preference for each status, as well as the desired timing, thereof.

Respondents were also queried about a variety of family and individual characteristics. In terms of their parents, participants were asked about the educational attainment of their mothers and fathers. The higher of the two (when two parents were present) was then included as a measure of the highest parental education, with responses including "eighth grade or less" (1), "beyond the 8th grade, but did not complete high school" (2), "high school degree" (3), "attended college, but did not finish degree" (4), "four-year college degree" (5), and "graduate or professional degree" (6). Maternal employment was also assessed, with respondents being queried about whether their 
mother was employed for pay outside the home (yes $=1$, no $=0$ ). Given that the importance of parental role models absolutely must be addressed in regard to the development of marriage and parenthood preferences, participants were asked: "For most of the time when you were growing up, did you think your parents' marriage was not too happy (1), just about average (2), happier than average (3), or very happy (4)." Given that previous studies have suggested that language can shape individuals' perceptions of relationships and the cultural meanings thereof (Moore 2009), respondents were also queried as to whether English was spoken in their homes $(1=$ yes, $0=$ no). In order to assess the extent of parental influence, participants were offered the following statement: "I would be willing to date someone of whom my parents/family did not approve." Responses ranged from "strongly disagree" (1) to "strongly agree" (5).

Individual characteristics were also examined within the survey. Respondents were asked to provide their age and sex, but were also asked about a variety of other traits. Within China, religious affiliation is relatively low, yet the presence of temples and shrines are quite common in almost every city and town. Since religion has been shown to significantly shape perceptions of marriage and family life (Roberts 2004), respondents were asked how often they visited a place of worship (e.g., church, mosque, shrine, temple), with responses ranging from "do not attend" (1) to "once or more per week" (6). A basic measure of self-esteem was included, using responses to the statement: "On the whole, I am satisfied with myself." Responses ranged from "strongly disagree" (1) to "strongly agree" (5). In regard to attitudes, respondents were asked about their beliefs concerning gender roles within the family context. The statements used in creating an index of gender attitudes included the following: (1) it is much better for everyone if the man earns the main living and the woman takes care of the home and family, (2) both husbands and wives should contribute to family income, (3) a husband should spend just as many hours doing housework as his wife, and (4) the spouse who earns the most money should have the most say in family decisions. Responses to each of these statements ranged from "strongly disagree" to "strongly agree." After inverting the coding schemes, the resultant combined measure of gender attitudes ranged across a five-point scale, with a higher score indicating more conservative/traditional gender role attitudes (Cronbach's alpha $=0.87$ ). Respondents were similarly asked about their pro-natalist attitudes by being asked to respond to the statement: "a person can have a fully satisfying life without having children." Responses ranged from "strongly agree" (1) to "strongly disagree" (5). A measure of school performance was also included, with respondents describing their overall grade performance. Responses ranged from "less than D's" (1) to "mostly A's" (8).

Given the complex nature of dating and dating relationships, multiple measures were utilized in these analyses. In regard to dating experiences, respondents were asked “thinking back about all of the dating experiences you've had, how long was the longest romantic relationship you have had?" Responses to this item ranged from "less than a week" (1) to "more than a year" (9). A measure of respondents' willingness to date outside of their own social groups was included through the combination of responses to three different questions. Respondents were asked if, in terms of dating partners, they would be willing to date someone from: (1) a different religion, (2) a different race or ethnicity, and (3) a different country. The responses to each item ranged from "yes," "no," and "maybe." Affirmative responses ("yes") to each were then combined to create 
a measure of desired heterogamy (Cronbach's alpha $=0.86$ ), with a range of 0 to 3 . Participants were asked how many of their close friends were currently dating or in a romantic relationship. Responses to this question ranged from "only a few or none of them" (1) to "all or almost all of them" (5). In order to examine individuals' adherence to more traditional dating expectations, respondents were offered the statement: "I would be willing to kiss on a first date." Responses ranged from "strongly disagree" (1) to "strongly agree" (5).

Finally, respondents were subsequently asked about the specific characteristics which they are looking for in a partner. Respondents were asked to indicate their preference for particular traits by stating whether each quality was "not at all important" (1) to "extremely important" (7). Of the particular traits which were queried, some were used to create indexed measures of a broader set of characteristics. The first of these, pragmatic, is created through the combination of four traits: well educated, wealthy, successful, and ambitious (Cronbach's alpha $=0.90$ ). The second, caring, is created through the combination of the following four traits: affectionate, loving, considerate, and kind (Cronbach's alpha $=0.86$ ). The third, appearance, is created from the combination of four traits: sexy, neat, attractive, and well dressed (Cronbach's alpha $=0.87$ ). Together, these three measures provide a broad assessment of qualities which the respondents might desire in a potential partner, all of which may be associated with their preferences concerning future marriage and parenthood. Within the analyses, both ordinary least squares regression models and logistic regression models will be utilized in order to estimate the relative impact of the individual and family characteristics upon marriage and fertility preferences.

\section{Results}

Table 1 presents the mean levels of marital and parental preferences among Chinese college students, by sex. As shown, a minority of both young women and men express the desire to marry, one day. Among females, 9.0\% expressed either agree or strong agreement to the query concerning the desire to marry, while $14.0 \%$ of males felt likewise. Although there is no statistical difference in the respective mean levels of females' and males' responses to this item, it is, nonetheless, worth noting that $62.4 \%$ of women either disagreed or strongly disagreed with this query, while $60.0 \%$ of males did likewise. This may suggest that there is a slightly higher aspiration for marriage among young Chinese men, as compared to young women, while at the same time, slightly more young women appear to be disinclined to pursue marriage. In regard to the timing of marriage, young women, on average, prefer to marry at 26.6 years of age, while young men prefer, on average, to marry at 27.9 years of age. The pattern appears to be consistent with the "marriage gradient," such that males tend to be slightly older at the time of first marriage, as compared to females. It is again worth noting, however, that substantially more males expressed the preference to marry at age 31 or above (9.5\%), as compared to females (1.7\%).

In regard to the preference for having children, both the majority of females and males appear to view two children as the preferred number. Among females, 63.0\% expressed the preference for two children, while $56.7 \%$ of males felt likewise. Comparatively fewer young adults expressed a preference for remaining childless $(7.4 \%$ of females, $4.1 \%$ of males), suggesting that the cultural expectations associated with 
Table 1 Mean levels of marital and parental preferences among Chinese college students, by sex

\begin{tabular}{lll}
\hline & Females & Males \\
\hline Want to marry & $3.74(0.95)$ & $3.63(0.99)$ \\
Strongly agree & $2.1 \%$ & $3.3 \%$ \\
Agree & 6.9 & 10.7 \\
Unsure & 28.6 & 25.9 \\
Disagree & 39.9 & 39.3 \\
Strongly disagree & 22.5 & 20.7 \\
Preferred age at marriage & 26.60 & $27.86^{* * *}$ \\
& $(5.00)$ & $(3.22)$ \\
20 and younger & $1.1 \%$ & $1.1 \%$ \\
21 to 25 & 31.5 & 22.2 \\
26 to 30 & 65.9 & 67.4 \\
31 to 35 & 1.7 & 8.6 \\
36 and older & 0.0 & 0.7 \\
Preferred number of children & $1.80(0.85)$ & $1.84(0.84)$ \\
None & $7.4 \%$ & $4.1 \%$ \\
1 & 19.0 & 25.6 \\
2 & 63.0 & 56.7 \\
3 or more & 10.6 & 13.7 \\
Preferred age at first birth & 27.74 & $29.59^{* * *}$ \\
20 and younger & $(2.51)$ & $(3.24)$ \\
31 to 25 & $1.3 \%$ & $0.0 \%$ \\
36 and older & 13.0 & 27.5 \\
$N$ & 77.6 & 2.9 \\
\hline
\end{tabular}

Note: standard deviations shown in parentheses; significance levels indicate difference between the means of females and males ${ }^{* * *} p<.01,{ }^{* *} p<.05,{ }^{*} p<.10$

childbearing remain quite salient in contemporary Chinese society. Females reported a preferred average age at first birth of 27.74, while among men, the comparable preference was 29.59 years of age. When considered alongside the preferred ages at marriage, these figures suggest that the typical young Chinese couple prefers to begin having children almost immediately.

Table 2 presents the mean levels of family and individual characteristics among Chinese college students, by sex. As shown, the parents of both young women and men were reported to have a relatively high level of educational attainment, with the typical parent having at least some college. Among females, approximately $83 \%$ reported that their mother was employed outside the home during their youth, while the corresponding maternal employment rate among males was $77 \%$. Both young females and males reported that their parents had relatively high levels of marital quality. Assuming that these responses are reliable, it would suggest that most young Chinese adults in the sample had positive role models concerning spousal roles and relationships. These role models may, understandably, influence young adults' preferences for both marriage and parenthood. English was spoken only in a small percentage of families ( $11 \%$ of women's families and $9 \%$ of men's). Interestingly, significantly more males 
Table 2 Mean levels of family and individual characteristics among Chinese college students, by sex

\begin{tabular}{lll} 
& Females & Males \\
\hline Highest parental education & $4.62(1.23)$ & $4.75(1.27)$ \\
Employed mother & $0.83(0.38)$ & $0.77^{*}(0.42)$ \\
Parents' marital quality & $3.87(1.03)$ & $3.99(1.20)$ \\
English spoken at home & $0.11(0.31)$ & $0.09(0.29)$ \\
Date without parent approval & $3.05(1.01)$ & $3.42^{* * *}(0.93)$ \\
Age & $21.39(9.21)$ & $21.30(7.04)$ \\
Religiosity & $1.86(1.20)$ & $1.91(1.23)$ \\
Longest dating relationship & $5.27(5.54)$ & $5.74(2.43)$ \\
Desires heterogamy & $1.08(1.22)$ & $1.13(1.23)$ \\
Number of friends dating & $3.04(1.09)$ & $3.15(1.01)$ \\
Willing to kiss on first date & $2.57(1.08)$ & $3.24^{* * *}(1.12)$ \\
Self-esteem & $3.47(0.99)$ & $3.56(0.94)$ \\
Conservative gender attitudes & $2.41(0.59)$ & $2.80^{* * *}(0.62)$ \\
Pro-natalist attitude & $2.69(1.13)$ & $2.65(1.06)$ \\
College grades & $2.20(0.96)$ & $2.37^{* *}(1.16)$ \\
Desired partner qualities & & $4.26^{* * *}(1.15)$ \\
Pragmatic & $4.76(1.08)$ & $5.12(1.09)$ \\
Caring & $5.25(1.05)$ & $4.74(1.11)$ \\
Appearance & $4.61(1.06)$ & \\
\hline
\end{tabular}

Note: $N=378$ females, 270 males; standard deviations shown in parentheses; significance levels indicate difference between the means of females and males

${ }^{* * *} p<.01,{ }^{* *} p<.05,{ }^{*} p<.10$

expressed a willingness to date someone without their parents' approval, as compared to females. It is possible that contemporary Chinese sons are simply more independent, or perhaps even rebellious in this regard.

Females and males in the sample were approximately of the same age (21.39 years of age among females, 21.30 among males). Young women and men were also similar in terms of their visitation to a place of worship, with the average respondent doing so several times each year. Males and females were also similar in regards to their dating relationships, with most having had a relationship lasting, on average, a few months. The desire among either sex to date someone from outside their own social groups (including religion, race/ethnicity, and nationality) was rather low. Of course, this must be taken in the context of the available pool of potential eligible dating partners, such that there is a general lack of such diversity in most Chinese university populations. Peer pressure to be involved in an intimate relationship may be somewhat tangible, as females and males reported that, on average, approximately half of their friends were currently in a dating relationship. Young men do express a significantly greater willingness to kiss on a first date, as compared to young women. While the difference between the sexes in this regard is not entirely surprising, it does, nonetheless, represent a possible departure from more conservative Chinese dating practices.

The reported levels of self-esteem were moderately high, with no significant differences shown between women and men. Males did espouse significantly more conservative gender attitudes, as compared to women. Once again, however, this must be taken with the patriarchal context of Chinese culture. In terms of espousing a more 
pro-natalist set of attitudes, neither young women nor young men regarded having children as being necessary for a satisfying life. Males did report a slightly higher grade performance, as compared to females. Finally, in regard to desired partner characteristics, females expressed a significantly higher preference for a partner with pragmatic qualities, as compared to males. Hence, females were more likely to be seeking a partner who is well educated, wealthy, successful, and ambitious. In terms of the qualities of being caring or in regard to appearance, there were no significant differences between the sexes. We will now examine how these various individual and familial characteristics are associated with marital and parental preferences.

Table 3 presents the results of logistic regression models of the preference to marry by sex. The models are both significant and yield a substantial amount of explanatory strength (with Nagelkerke r-squares of .133 and .220 for females and males, respectively). These models are presented separately for females and males, so as to allow for direct comparison of the respective effects. In previous analyses (not shown) of these data, the statistical validity of separating the models by sex was ascertained and verified. Among females, more conservative gender role attitudes are shown to increase the likelihood of desiring marriage $(b=.644)$. Given that traditional cultural expectations typically view marriage as a normative expectation for women, this association is somewhat expected. Interestingly, though, conservative gender role attitudes are not shown to be significant in the model for males' desire to marry. Among females, higher levels of

Table 3 Logistic regression models of desire to marry among Chinese college students, by sex

\begin{tabular}{|c|c|c|}
\hline & \multicolumn{2}{|l|}{ Want to marry } \\
\hline & Females & Males \\
\hline Highest parental education & $-.117(.120)$ & $-.092(.130)$ \\
\hline Employed mother & $-.460(.354)$ & $.528(.430)$ \\
\hline Parents' marital quality & $.171(.133)$ & $.168(.137)$ \\
\hline English spoken at home & $.558(.428)$ & $1.278^{* * *}(.508)$ \\
\hline Date without parent approval & $-.076(.147)$ & $.434^{* *}(.193)$ \\
\hline Age & $.000(.018)$ & $.036 *(.019)$ \\
\hline Religiosity & $.073(.120)$ & $.070(.131)$ \\
\hline Longest dating relationship & $.005(.025)$ & $.001(.076)$ \\
\hline Desires heterogamy & $.164(.120)$ & $.173(.144)$ \\
\hline Number of friends dating & $.007(.138)$ & $.298^{*}(.175)$ \\
\hline Willing to kiss on first date & $.127(.141)$ & $-.102(.161)$ \\
\hline Self-Esteem & $.277^{*}(.153)$ & $.376^{* *}(.193)$ \\
\hline Conservative gender attitudes & $.644^{* *}(.259)$ & $.052(.270)$ \\
\hline Pro-natalist attitude & $-.065(.132)$ & $.212(.165)$ \\
\hline College grades & $-.265^{*}(.161)$ & $.051(.176)$ \\
\hline \multicolumn{3}{|l|}{ Desired partner qualities } \\
\hline Pragmatic & $.192(.224)$ & $.478^{* *}(.223)$ \\
\hline Caring & $-.180(.198)$ & $-.677^{* * *}(.221)$ \\
\hline Appearance & $.040(.211)$ & $.039(.246)$ \\
\hline Nagelkerke $R$-square & .133 & .220 \\
\hline-2 log likelihood & 321.408 & 239.606 \\
\hline
\end{tabular}

Note: standard error shown in parentheses; $N=378$ females, 270 males Significance levels: ${ }^{* * *} p<.01,{ }^{* *} p<.05,{ }^{*} p<.10$ 
self-esteem are also associated with a higher desire to marry $(b=.277)$. It is possible that higher self-esteem may also increase confidence that they will be able to secure a partner, one day. However, higher grades in college were shown to negatively impact females' desire to marry $(b=-.265)$. Here, females with better performance in school may be placing a higher priority upon their educational and occupational goals, in their consideration of marriage.

Among males, the use of English at home is shown to significantly increase the likelihood that they will desire to marry $(b=1.278)$. It is conceivable that the use of English at home may also be associated with higher aspirations for status attainment, thus suggesting that such males may be more goal-oriented about future statuses (including marriage). The willingness to date without parental approval is also positively linked to a higher likelihood of the desire to marry among males $(b=.434)$. Males are similarly shown to be subject to peer pressure and age effects, as their desire to marry is also positively linked to the number of their friends who are dating, and their own age ( $b=.298$ and .036 , respectively). As was shown in the female model, higher levels of self-esteem are shown to significantly increase the likelihood that males will desire to marry $(b=.376)$. Partner qualities are shown to yield salient effects among males, as well. Males who express a preference for more pragmatic qualities in a partner are likely to have higher desires to marry, while those who prefer more caring qualities in a partner are likely to have lower desires to marry.

Table 4 shows the OLS regression models of the desired age at first marriage, for females and males. In the model of desired age at marriage, parental educational attainment is again shown to be negatively associated with females' preferences $(b=-.213)$. Thus, young women whose parents have higher levels of educational attainment are likely to prefer an earlier age at marriage. This seems rather contradictory, but it may be that daughters may feel pressured to satisfy the marital expectations of parents with higher educational attainment, who perhaps regard the educational attainment of their daughters as beneficial for their financial futures, but detrimental for their marital and fertility aspirations. The possible influence of fertility expectations is also evident in the model, as females with more pro-natalist attitudes appear to prefer a younger age at marriage $(b=-.226)$. The willingness to kiss on a first date is similarly shown to be negatively associated with females' desired age at marriage $(b=-.224)$.

Among young men, higher levels of parental educational attainment are also shown to be negatively associated with the desired age at marriage $(b=-.313)$. It is certainly noteworthy that this association is relatively the same for both sexes. Among males, though, the use of English in their homes yields a strong positive association with desired age at marriage $(b=1.877)$. Several possibilities exist in regard to the meaning of this association, not the least of which is the role of English skills in both future educational and occupational opportunities, both of which may require that marriage be effectively delayed for young men. In contrast to young women, males who are willing to kiss on a first date are shown to desire a higher age at marriage $(b=.422)$. Understandably, females and males typically approach intimate relationships with different attitudes and expectations. In this instance, young men who are more "progressive" in their beliefs concerning dating may not necessarily regard marriage as the primary goal of dating relationships. Finally, it is also important to note that males who desire a more pragmatic partner seem to also desire a younger age at marriage $(b=-.611)$. 
Table 4 Ordinary least squares regression models of desired age at marriage among Chinese college students, by sex

\begin{tabular}{lll}
\hline & Desired age at marriage & \\
\cline { 2 - 3 } & Females & Males \\
\hline Highest parental education & $-.213^{* *}(-.118)$ & $-.313^{* *}(-.124)$ \\
Employed mother & $.278(.047)$ & $.654(.086)$ \\
Parents' marital quality & $-.174(-.081)$ & $-.098(-.037)$ \\
English spoken at home & $-.271(-.038)$ & $1.877^{* * *}(.172)$ \\
Date without parent approval & $-.103(-.047)$ & $.057(.017)$ \\
Age & $.020(.084)$ & $.070^{* * *}(.153)$ \\
Religiosity & $.004(.002)$ & $-.279^{*}(-.106)$ \\
Longest dating relationship & $.035(.086)$ & $-.003(-.002)$ \\
Desires heterogamy & $.090(.049)$ & $-.021(-.008)$ \\
Number of friends dating & $-.183(-.089)$ & $-.029(-.009)$ \\
Willing to kiss on first date & $-.224^{* *}(-.108)$ & $.422^{* *}(.148)$ \\
Self-Esteem & $-.082(-.036)$ & $-.068(-.020)$ \\
Conservative gender attitudes & $-.248(-.066)$ & $.265(.052)$ \\
Pro-natalist attitude & $-.226^{* *}(-.115)$ & $-.120(-.040)$ \\
College grades & $.083(.036)$ & $-.005(-.002)$ \\
Desired partner qualities & & .122 \\
Pragmatic & $-.091(-.044)$ & 1.937 \\
Caring & $-.078(-.036)$ & $-.611^{* * *}(-.220)$ \\
Appearance & $.068(.032)$ & $.03(.035)$ \\
R-square & .083 & $.070)$ \\
\hline
\end{tabular}

Note: standardized coefficients shown in parentheses; $N=378$ females, 270 males; Significance levels: ${ }^{* * *} p<.01,{ }^{* *} p<.05,{ }^{*} p<.10$

While pragmatic partner qualities encompass notions of wealth and success, this association may suggest that young Chinese males simply want to quickly locate a spouse who can also fulfill a provider role within marriage.

Table 5 presents the ordinary least squares regression models of parental preferences among young women and men, including both their desired number of children and their desired age at the time of first birth. The models are all significant and yield substantial explanatory strength, with $\mathrm{r}$-squares ranging from .080 to .186 . In the model of women's desired number of children, religiosity is shown to be positively associated ( $b=.071)$, suggesting that greater visitations to places of worship is associated with desire for more children. Among those who expressed a religious affiliation, Buddhism was the highest one reported (17\%), while the majority of respondents did not claim a specific religious affiliation. However, even Buddhism, while a pro-family faith, does not explicitly address the issue of fertility in a manner of other religions. In this instance, higher religiosity may simply be related to greater traditional beliefs concerning marriage and family life, which, in turn, would be associated with childbearing. Females' pro-natalist attitudes are also shown to be positively associated with the desired number of children $(b=.131)$, suggesting that ideology and faith do play a salient role in the childbearing preferences of young Chinese women. On the other hand, higher college grades yield a negative association with the desired number of children $(b=-.089)$, 
Table 5 Ordinary least squares regression models of parental preferences among Chinese college students, by sex

\begin{tabular}{|c|c|c|c|c|}
\hline & \multicolumn{2}{|c|}{ Desired no. of children } & \multicolumn{2}{|c|}{ Desired age at first birth } \\
\hline & Females & Males & Females & Males \\
\hline Highest parental education & $-.027(-.039)$ & $.017(.025)$ & $-.046(-.023)$ & $-.167(-.066)$ \\
\hline Employed mother & $-.035(-.016)$ & $-.028(-.014)$ & $.512(.077)$ & $.286(.037)$ \\
\hline Parents' marital quality & $.029(.035)$ & $.086^{* *}(.122)$ & $-.199(-.082)$ & $-.186(-.069)$ \\
\hline English spoken at home & $-.009(-.003)$ & $.484^{* * *}(.170)$ & $-.692(-.087)$ & $1.784^{* * *}(.162)$ \\
\hline Date without parent approval & $-.009(-.010)$ & $.046(.050)$ & $-.057(-.023)$ & $-.054(-.016)$ \\
\hline Age & $-.005(-.055)$ & $.012^{*}(.104)$ & $.016(.059)$ & $.062^{* *}(.134)$ \\
\hline Religiosity & $.077^{* *}(.108)$ & $.116^{* * *}(.169)$ & $-.023(-.011)$ & $-.235(-.089)$ \\
\hline Longest dating relationship & $-.013(-.084)$ & $.022(.065)$ & $.034(.075)$ & $-.008(-.006)$ \\
\hline Desires heterogamy & $.071^{* *}(.102)$ & $.050(.073)$ & $.029(.014)$ & $.081(.031)$ \\
\hline Number of friends dating & $-.041(-.052)$ & $.031(.037)$ & $-.045(-.020)$ & $-.471^{* *}(-.147)$ \\
\hline Willing to kiss on first date & $-.007(-.008)$ & $-.015(-.021)$ & $-.145(-.062)$ & $.498^{* * *}(.173)$ \\
\hline Self-esteem & $.040(.047)$ & $.038(.043)$ & $.014(.006)$ & $.136(.039)$ \\
\hline Conservative gender attitudes & $.131 *(.092)$ & $-.051(-.038)$ & $-.400^{*}(-.095)$ & $-.022(-.004)$ \\
\hline Pro-natalist attitude & $.131^{* * *}(.174)$ & $.138^{* * *}(.175)$ & $-.266^{* *}(-.120)$ & $-.158(-.052)$ \\
\hline College grades & $-.089^{*}(-.100)$ & $-.096^{* *}(-.132)$ & $.147(.056)$ & $.049(.018)$ \\
\hline \multicolumn{5}{|l|}{ Desired partner qualities } \\
\hline Pragmatic & $.022(.028)$ & $-.098^{*}(-.134)$ & $-.128(-.055)$ & $-.412^{*}(-.147)$ \\
\hline Caring & $-.009(-.011)$ & $.081(.106)$ & $.111(.047)$ & $-.005(-.002)$ \\
\hline Appearance & $.052(.064)$ & $-.090(-.119)$ & $-.145(-.061)$ & $.104(.035)$ \\
\hline R-square & .089 & .186 & .080 & .133 \\
\hline $\mathrm{F}$ & 1.945 & 3.189 & 1.725 & 2.143 \\
\hline
\end{tabular}

Note: Standardized coefficients shown in parentheses; $N=378$ females, 270 males; Significance levels: ${ }^{* * *} p<.01,{ }^{* *} p<.05,{ }^{*} p<.10$

which again suggests that educational goals (and, perhaps, occupational goals) may detract from females' fertility preferences.

Among males, parental marital quality again is shown to be positively associated with parental preferences $(b=.086)$. It is rather intriguing that the influence of parental marital quality appears to significantly influence the marital and parental preferences of males, but not females. The notable influence of English being spoken at home is also shown to be significantly associated with males' desired number of children $(b=.484)$. In a manner consistent with that shown among females, young Chinese men with higher reported religiosity appear to have desires for more children $(b=.116)$. While the interpretation of this association is open to debate, the meaningful influence of religiosity is quite evident, at least in terms of its impact upon young Chinese adults' preferences for having children. The pro-natalist attitudes of young men are also shown to be positively associated with their desired number of children $(b=.138)$. While religiosity and pro-natalist attitudes appear to increase the desired number of children among males, college grades are shown to yield a negative association $(b=-.096)$. In addition, the desire for a partner with more pragmatic qualities is negatively associated with males' desired number of children $(b=-.098)$.

In regard to the desired age at first birth, females with greater pro-natalist attitudes appear to prefer a younger age $(b=-.266)$. Hence, females who espouse pro-natalist 
attitudes are likely to want to have children sooner, rather than later. Among males, the influence of English being spoken at home is again evident $(b=1.784)$, suggesting that greater English skills both lower males' desired number of children and increase their desired age at first birth. Such language skills may be associated with educational and/ or occupational goals among young men. Interestingly, having more friends who are currently dating is associated with a lower desired age at first birth $(b=-.471)$ among males. However, the willingness to kiss on a first date yields a positive association ( $b=.498)$ with males' desired age at first birth. Again, more culturally progressive behaviors (i.e., kissing on a first date) may suggest that such males have eschewed traditional expectations concerning both marriage and fertility. In a manner consistent with their desired number of children, males' desire for a partner with more pragmatic qualities is shown to be negatively associated $(b=-.412)$ with their desired age at first birth. Clearly, the combination of parental characteristics, dating behaviors, ideologies, and even religiosity yields a variety of rather intriguing associations with both the marriage and parental preferences of young Chinese women and men. The meanings and potential implications of these effects will now be addressed.

\section{Discussion and conclusions}

This study was initiated to provide an exploration of marriage and parenthood preferences among college students in contemporary China. Although the participants were randomly selected, the sample is relatively small and select; thus, any broad generalizations must be offered with these limitations in mind. Nonetheless, the analyses do provide a unique view into the preferences of young adults, concerning marriage and parenthood, and also illustrate some of the tangible differences between the preferences of women and men.

Overall, the young women and men within this college sample expressed a relatively weak desire to marry. Although there is universal acknowledgement of marriage as an appropriate, and even necessary, adult status within traditional Chinese culture, this lower level of desire to marry is to be anticipated, particularly given the legal age requirements for marriage. It was rather noteworthy, however, that comparatively more males (14\%) openly expressed a positive desire to marry. This may indicate their awareness of the skewed sex ratio in China and the obvious dilemma which it presents to young men who are seeking a prospective wife (see Trent and South 2011). On the basis of their expressed preferences, the average female would marry around 27 years of age, while the average male would marry around 28 years of age. Extrapolating these preferences to the larger population, it would suggest that the "marriage gradient," wherein husbands are slightly older than their wives, on average, will remain a salient feature of Chinese marriages. In regards to parenthood, both sexes expressed a preference for slightly less than two children (although two, precisely, was the number of children preferred by the majority of both females and males). The preferred timing of first birth yielded a fascinating pattern, as women preferred to have their first child at approximately 28 years of age, while men preferred to have theirs at approximately 30 years of age. In conjunction with the preferred age at marriage, this suggests that the average female wants to have her first child roughly 1 year after getting married, while the average male wants to wait an additional year. While the difference between the preferences of women and men is important to note, these preferences suggest that 
the average Chinese couple will want to start having children soon after their marriage. Hence, the "honeymoon" phase, with no children present, is likely to be quite short. This seeming rush to have the first child is consistent with findings of previous studies (e.g., Hong 2006; Qian and Knoester 2015).

Gender differences were noted within the regression models of wanting to marry, as well as the preferred timing of marriage. Females were more likely to prefer marriage when they had higher levels of self-esteem and more conservative gender attitudes. Understandably, self-esteem may be associated with confidence and comfort of being in an intimate relationship, while conservative gender attitudes may reflect the traditional cultural expectations for marriage itself.

Higher grades in college were also associated with a lower preference to marry among females. The consistent valuation of education and educational attainment in Chinese culture is perhaps embedded within the preferences for marriage among young women, in particular. Among young men, on the other hand, the use of English at home was associated with a stronger desire to marry. Clearly, language yields a substantial influence upon males' preferences for marriage, yet other qualities associated with English usage may be at play here, as will be addressed. Similar to their female counterparts, males with higher levels of self-esteem were more likely to desire marriage. However, the personal qualities desired in a partner significantly affected males, yet not females, in this regard. In particular, males who desired more pragmatic qualities, such as being successful, were more likely to desire marriage, while those who desired more caring qualities, such as being loving, were less likely to desire marriage. These distinctions may reflect the nature of dating, specifically in terms of its objectives. Simply, young men who are looking for a romantic partner may be more concerned with dating (a non-committal relationship), while those who are looking for a pragmatic partner are perhaps looking specifically for a wife. The role models which parents represent will likely have an impact upon children's perceptions of marriage, but it is certainly intriguing to note that sons, more so than daughters, are affected by their parents' marital quality. Both females and males were shown to prefer lower ages at marriage when their parents had higher levels of educational attainment. This similarity, however, does not necessarily imply that females and males are experiencing the same impact of parents' educational attainment. Among females, it is quite possible that parents with higher educational attainment want their daughters to be successful, in both the educational and occupational regard, but perhaps view educational attainment as a potential impediment to getting married. Among males, on the other hand, parents with higher educational attainment may exert greater pressure for their sons to hurry and find a spouse while they are younger, and the pool of potential partners is larger. It was also quite interesting that the willingness to kiss on a first date was negatively associated with females' preferred age at marriage, while it was positively associated with males' preferred age. Kissing on a first date is still relatively uncommon in China and perhaps represents a rather progressive attitude concerning dating and intimate relationships. Young women and men, however, may view this behavior differently, with females perhaps associating kissing with the establishment of a more lasting relationship, while males may regard kissing (and other aspects of sexuality) as the desired goal of dating (as opposed to viewing relationships as a path to marriage). Further study is certainly warranted on this finding, but it does clearly suggest that Chinese 
females and males have both distinct perceptions and preferences concerning intimate relationships.

In regard to preferences for childbearing, males were again positively influenced by their parents' marital quality, which illustrates the unique dynamics of parent-son relationships within Chinese culture. It was also interesting to note that religiosity yielded strong positive associations with the preference number of children for both females and males. Buddhism, the predominant faith within China, does not offer a strong pro-natalist perspective, yet the relative impact of religiosity suggests that perhaps the traditional expectations of family formation, and specifically bearing children, are grounded within religious beliefs. The pro-natalist attitudes of individuals did, of course, have a strong positive association with the preferred number of children. Among females, pro-natalist attitudes were also positively associated with the preferred age at first birth. Males were significantly influenced by the use of English at home, with such usage being associated with a higher preferred number of children and a later age at first birth. The use of English may be related to the occupational goals of young men, as language skills will likely yield better financial opportunities for them, thus making family formation (i.e., childbearing) more affordable, and perhaps expose males to more non-traditional values and behaviors. In this regard, the use of English may also indicate a more progressive set of traits, particularly among males, which prompt them to shift away from traditional cultural expectations (see Inkeles 1996).

Overall, the results suggest that familial traits, such as parents' educational attainment and marital quality, still have a substantial influence over young adults' preferences concerning marriage and childbearing. This would certainly be consistent with the long cultural history of family control over such decisions. At the same time, the influence of individual traits, such as individual attitudes, school performance, peers, partner qualities, and dating behaviors, was quite substantial. Marriage and parenthood are statuses to which the overwhelming majority of young Chinese adults aspire, yet these statuses and the very nature of family itself are culturally defined. Much has been made of the seeming "tug-of-war" in which many young adults find themselves-with traditional cultural expectations prompting them to remain obedient to their parents and exercise filial piety, while social transformations within China are encouraging individualism, materialism, and a consumption-based culture. For contemporary young females and males, the development of preferences concerning marriage and parenthood is taking place within a context where the "traditional" and "progressive" notions of family are clearly in the midst of a substantial amount of social change, perhaps suggesting that the globalization of cultural standards concerning family may be occurring. In addition, the context in which these changes are occurring is not necessarily uniform throughout China. Researchers have posited that, despite the substantial changes which have happened over the past half century, there are still social and geographic "pockets" in which the more traditional components of Chinese culture tend to dominate (Santos and Harrell 2017). Future studies should attempt to more precisely discern this possibility and examine how gender differences in marriage and fertility preferences may be affected by such globalization effects. 


\section{Funding}

This study received no external funding.

\section{Availability of data and materials}

The data used in this article are available, upon request, from the authors (slblair@buffalo.edu and tmadigan@mansfield.edu).

\section{Authors' contributions}

SB and TM contributed equally to the study conception and survey design. SB and TM equally participated in the collection of the survey data. SB performed the statistical analyses. SB prepared the initial draft of the manuscript. SB and TM were both responsible for the critical revisions of the manuscript. Both authors read and approved the final manuscript.

\section{Competing interests}

The authors declare that they have no competing interests.

\section{Publisher's Note}

Springer Nature remains neutral with regard to jurisdictional claims in published maps and institutional affiliations.

\section{Author details}

'Department of Sociology, The State University of New York, Buffalo, NY 14260, USA. ${ }^{2}$ Department of Sociology,

Mansfield University, Mansfield, PA 16933, USA.

\section{Received: 4 April 2018 Accepted: 11 October 2018}

Published online: 30 October 2018

\section{References}

Attane, I. 2016. Second child decisions in China. Population and Development Review 42 (3): 519-536.

Basten, S., and Q. Jiang. 2015. Fertility in China: an uncertain future. Population Studies 69 (1): 97-105.

Becker, G.S. 1981. A treatise of the family. 2nd ed. Cambridge: Harvard University Press.

Bian, F., J. Logan, and Y. Bian. 1998. Intergenerational relations in urban China: proximity, contact, and help to parents. Demography 35: 115-124.

Cai, Y., and F. Wang. 2014. From collective synchronization to individual liberalization: (re)emergence of late marriage in Shanghai. In Sexuality and marriage in cosmopolitan China, ed. D. Davis and S. Freedman, 97-117. Redwood City: Stanford University Press.

Chen, F. 2009. Family division in China's transitional economy. Population Studies 63(1):53-69.

Chen, H., Luo, S., Yue, G., Xu, D., and Zhaoyang, R. 2009. Do birds of a feather flock together in China? Personal Relationships 16:167-186.

Chi, X., van de Bongardt, D., and Hawk, S.T. 2015. Intrapersonal and interpersonal sexual behaviors of Chinese university students: Gender differences in prevalence and correlates. The Journal of Sex Research 52(5):532-542.

Chu, C.Y.C., and Yu, R. 2010. Understanding Chinese families: A comparative study of Taiwan and southeast China. Oxford, UK: Oxford University Press.

Chui, C.Y., and Y.Y. Hong. 2006. Social psychology of culture. New York: Psychology Press.

Cooke, F.L. 2001. Equal opportunity? The role of legislation and public policies in women's employment in China. Gender in Management 16 (7/8): 334-348.

Davin, D. 2007. Marriage migration in China and East Asia. Journal of Contemporary China 16 (50): 83-95.

Davis, D.S., and S. Harrell. 1993. Introduction: the impact of post-Mao reform on family life. In Chinese families in the post-Mao era, ed. D. Davis and S. Harrell, 1-24. Berkeley: University of California Press.

Ellingson, S., E.O. Laumann, A. Paik, and J. Mahay. 2004. The theory of sex markets. In The sexual organization of the city, ed. E. O. Laumann, S. Ellingson, J. Mahay, A. Paik, and Y. Youm, 3-38. Chicago: The University of Chicago Press.

Evans, H. 1997. Women and sexuality in China: dominant discourses of female sexuality and gender since 1949. Cambridge: Polity Press.

Feeney, G., and F. Wang. 1993. Parity progression and birth intervals in China: the influence of policy in hastening fertility decline. Population and Development Review 19 (1): 61-101.

Feng, W., and Y. Quanhe. 1996. Age at marriage and the first birth interval: the emerging change in sexual behavior among young couples in China. Population and Development Review 22 (2): 299-320.

Fincher, L.H. 2014. Leftover women: the resurgence of gender inequality in China. London: Zed Books.

Gaetano, A. 2008. Sexuality in diasporic space: rural-to-urban migrant women negotiating gender and marriage in contemporary China. Gender, Place, and Culture 15 (6): 629-645.

Gittings, J. 2006. The changing face of China: from Mao to market. Oxford: Oxford University Press.

Guthrie, D. 2008. China and globalization: the social, economic and political transformation of Chinese society. New York: Routledge.

Hatfield, E. and Rapson, R. L. 2005. Social justice and the clash of cultures. Psychological Inquiry 16(4):172-175.

Hesketh, T. 2009. Too many males in China: the causes and consequences. Significance 6 (1): 9-13.

Hong, Y. 2006. Marital decision-making and the timing of first birth in rural China before the 1990s. Population Studies 60 (3): 329-341.

Hu, Y., and J. Scott. 2016. Family and gender values in China: generational, geographic, and gender differences. Journal of Family Issues 37 (9): 1267-1293.

Hynie, M., R.N. Lalonde, and N. Lee. 2006. Parent-child value transmission among Chinese immigrants to North America: the case of traditional mate preferences. Cultural Diversity and Ethnic Minority Psychology 12 (2): 230-244. 
Inkeles, A. 1996. Making men modern: on the causes and consequences of individual change in six developing countries. In Comparing nations and cultures: readings in a cross-cultural perspective, ed. A. Inkeles and M. Sasaki, 571-585. Englewood Cliffs, New Jersey: Prentice Hall.

Jankowiak, W., and X. Li. 2014. The decline of the chauvinistic model of Chinese masculinity. Chinese Sociological Review 46 (4): 3-18.

Jiang, Q., M.W. Feldman, and S. Li. 2014. Marriage squeeze, never-married proportion, and mean age at first marriage in China. Population Research Policy Review 33: 189-204.

Jiawei, H. 2015. Changes in the Chinese population's fertility intentions: 1980-2011. Social Sciences in China 36 (1): $46-63$.

Jones, G.W., and B. Gubhaju. 2009. Factors influencing changes in mean age at first marriage and proportions never marrying in the low-fertility countries of East and Southeast Asia. Asian Population Studies 5: 237-265.

Lee, J., and F. Wang. 1999. One quarter of humanity: Malthusian mythology and Chinese realities, 1700-2000. Cambridge: Harvard University Press.

Lei, Y. 2005. Love and reason in the ivory tower: report on investigating issues concerning dating and love among contemporary college students. Zhenzhou: Henan University Press.

Li, E.B.C. 1994. Modernization: its impact on families in China. In Marriage and the family in Chinese societies: selected readings, ed. P.L. Lin, K. Mei, and H. Peng, 39-44. Indianapolis: University of Indianapolis Press.

Li, Y., and A. Xu. 2004. Ze Ou Mo Shi He Xing Bie Yan Jiu - Xi Fang LiLun He Ben Tu Jing Yan Zi Liao De Jie Shi. Qing Nian Yan Jiu 10: 1-11.

Liu, J. 2012. Does cram schooling matter? Who goes to cram schools? Evidence from Taiwan. International Journal of Educational Development 32: 46-52.

Liu, Z. 2005. The inspiration from a village. China's National Conditions and Strength 11: 41-43.

Mason, K.O. 1987. The impact of women's social position on fertility in developing countries. Sociological Forum 2 (4): 718-745.

McDonald, P. 2013. Societal foundations for explaining low fertility: gender equity. Demographic Research 28: 981-994.

Moore, J.D. 2009. Visions of culture: an introduction to anthropological theories and theorists. New York: Altamira Press.

Nakano, L. 2016. Single women and the transition to marriage in Hong Kong, Shanghai, and Tokyo. Asian Journal of Social Science 44: 363-390.

Ono, H. 2003. Women's economic standing, marriage timing, and cross-national contexts of gender. Journal of Marriage and Family 65: 275-286.

Parrish, W.L., and J. Farrer. 2000. Gender and family. In Chinese urban life under reform: the changing social contract, ed. W. Tang and W.L. Parish, 232-270. Cambridge: Cambridge University Press.

Peng, Y. 2004. An exploration into the phenomenon of involuntary bachelors in poverty-stricken area. Youth Studies 6: 18-20. Pimentel, E.E. 2000. Just how to I love thee?: marital relations in urban China. Journal of Marriage and Family 62: 32-47.

Piotrowski, M., Y. Tong, Y. Zhang, and L. Chao. 2016. The transition to first marriage in China, 1966-2008: an examination of gender differences in education and Hukou status. European Journal of Population 32: 129-154.

Qian, Y., and C. Knoester. 2015. Parental status and subjective well-being among currently married individuals in China. Journal of Family Issues 36 (10): 1351-1376.

Qian, Y., and Z. Qian. 2014. Gender divide in urban China: singlehood and assortative mating by age and education. Demographic Research 31: 1337-1364.

Roberts, K.A. 2004. Religion in sociological perspective. New York: Thomson Wadsworth.

Santos, G., and S. Harrell. 2017. Transforming patriarchy: Chinese families in the twenty-first century. Seattle: University of Washington Press.

Shek, D.T.L. 2006. Chinese family research puzzles, progress, paradigms, and policy implications. Journal of Family Issues 27: 275-284.

Sprecher, S. 1988. Investment model, equity, and social support determinants of relationship commitment. Social Psychology Quarterly 51: 318-328.

Tang, S., and J. Zhou. 2000. Dating attitudes and behaviors of American and Chinese college students. The Social Science Journal 37 (1): 67-78.

Thornton, A. 2005. Reading history sideways: the fallacy and enduring impact of the developmental paradigm on family life. Chicago: University of Chicago Press.

Tian, F.F. 2013. Transition to first marriage in reform-era urban China: the persistent effect of education in a period of rapid change. Population Research \& Policy Review 32 (4): 529-552.

To, S. 2015. Late marriage among professional women and its consequences. New York: Routledge.

Trent, K., and S.J. South. 2011. Too many men? Sex ratios and women's partnering behavior in China. Social Forces 90 (1): 247-268.

Wang, H., and D.A. Abbott. 2013. Waiting for Mr. Right: the meaning of being a single educated Chinese female over 30 in Beijing and Guangzhou. Women's Studies International Forum 40: 222-229.

Willis, R. 1987. What have we learned from the economics of the family? American Economic Review 77: 68-81.

Wu, D.Y.H. 1996. Chinese childhood socialization. In The handbook of Chinese psychology, ed. M.H. Bond, 143-154. Hong Kong: Oxford University Press.

Wu, X., H. Ye, and G.G. He. 2014. Fertility decline and women's status improvement in China. Chinese Sociological Review 46 (3): $3-25$.

Wu, X., and Z. Zhang. 2010. Changes in educational inequality in China, 1990-2005; evidence from the population census data. Research in Sociology of Education 17: 123-152.

Xia, Y.R., and Z.G. Zhou. 2003. The transition of courtship, mate selection, and marriage in China. In Mate selection across cultures, ed. Hamon and Ingoldsby. Thousand Oaks: Sage.

$\mathrm{Xu}, \mathrm{X} .1994$. The determinants and consequences of the transformation from arranged marriages to free-choice marriages in Chengdu, PRC. In Marriage and the family in Chinese societies: selected readings, ed. P.L. Lin, K. Mei, and H. Peng, $249-266$. Indianapolis: University of Indianapolis Press.

Xu, X., J. Ji, and Y. Tung. 2000. Social and political assortative mating in urban China. Journal of Family Issues 21 (1): $47-77$.

Xu, X., and M.K. Whyte. 1990. Love matches and arranged marriages: a Chinese replication. Journal of Marriage and the Family 52 (3): 709-722. 
Yan, H. 2003. Specialization of the rural: Reinterpreting the labor mobility of rural young women in post???Mao China. American Ethnologist 30(4):578-596.

Yang, R. 2011. Between traditionalism and modernity: changing values on dating behavior and mate selection criteria. International Review of Modern Sociology 37 (2): 265-287.

Yingchun, J. 2015. Between tradition and modernity: "Leftover" women in Shanghai. Journal of Marriage and Family 77 (5): 1057-1073.

Yu, J., and Y. Xie. 2015. Changes in the determinants of marriage entry in post-reform urban China. Demography 52 (6): 1869-1892.

Submit your manuscript to a SpringerOpen ${ }^{\odot}$ journal and benefit from:

- Convenient online submission

- Rigorous peer review

- Open access: articles freely available online

- High visibility within the field

- Retaining the copyright to your article

Submit your next manuscript at $\boldsymbol{\nabla}$ springeropen.com 